\title{
Body Weight Perception and Weight Loss Practices among Private College Students in Kelantan State, Malaysia
}

\author{
Salziyan Badrin ${ }^{1, *}$, Norwati Daud², Shaiful Bahari Ismail ${ }^{1}$ \\ 'Department of Family Medicine, School of Medical Sciences, Universiti Sains Malaysia, Kubang Kerian, Malaysia \\ ${ }^{2}$ Faculty of Medicine, Universiti Sultan Zainal Abidin, Kuala Terengganu, Malaysia
}

Background: Body image is associated with the perception of people on themselves. Influencing factors are generated internally and/or externally. The most common issue pertaining to body image is body weight and weight loss. This study aimed to determine the association between body weight perception and weight loss practices among college students.

Methods: A cross-sectional study was conducted involving 297 college students from private nursing colleges in the state of Kelantan, Malaysia. A self-administered questionnaire was used to assess sociodemographic characteristics, body weight perception, and weight loss methods. Weight and height were measured, and body mass index (BMI) was calculated based on weight and height measurement. The World Health Organization BMI cutoffs were applied in the study.

Results: More than half (54.2\%) of college students perceived their weight correctly as per actual measured BMI. A total of $51.5 \%$ of participants had tried various methods to reduce their weight. Body weight perception is associated with weight loss practices (odds ratio, $0.31 ; 95 \%$ confidence interval, $0.19-0.50 ; \mathrm{P}<0.001$ ) adjusted for sex, marital status, and status of having obese family members. Those who had correct body weight perception were less likely to engage in weight loss practice. Food intake restriction (42.4\%) is the most popular weight reduction method among students in nursing colleges. Over a quarter of the participants chose physical exercise (25.3\%) to reduce their weight, and a small number engaged in unhealthy weight loss practices.

Conclusion: Body weight perception is an important factor that influences the practice to reduce weight especially among young adult group and college students.

Keywords: Body Weight; Perception; Weight Loss; Body Mass Index

Received: November 20, 2017, Accepted: December 20, 2017

*Corresponding Author: Salziyan Badrin https://orcid.org/0000-0002-7353-2839

Tel: +60-09-7673000 (ext 6608), Fax: +60-09-767 3370, E-mail: salziyan@usm.my 


\section{INTRODUCTION}

Approximately 2 billion people aged 18 years and above are overweight, and more than half a billion are obese. ${ }^{1)}$ Decrease physical activity, unhealthy dietary habits, and low energy consumption are among the factors contributing to the increasing number of overweight and obese population. ${ }^{2,3)}$ The trend must be addressed as it contributes to the development of cardiovascular disease and its risk factors, which increases the burden on the economy and contributes toward psychosocial consequences. ${ }^{4)}$

According to the World Health Organization (WHO), a person with optimum health should maintain a body mass index (BMI) of 18.5 to $24.9 \mathrm{~kg} / \mathrm{m}^{2}{ }^{1)}$ In contrast, perceiving being underweight as having an ideal weight may lead to physical and mental health disorders. ${ }^{5,6)}$ It could also lead up to being involved in health-compromising behaviors such as illegal and inappropriate substance usage and, later, increasing the risk for suicidal ideation and attempt. ${ }^{7,8)}$

A few studies among adolescents found that those who misperceived their body weight are engaged in unhealthy diet and inappropriate weight reduction practices, which can jeopardize their growth. ${ }^{8,9)}$ Studies among children and adolescent population suggested that accuracy of perceiving body weight plays a role in an individual's nutritional habit and weight managing activities..$^{10,11)}$

The study on body weight perception was mainly carried out among children and adolescent age groups. ${ }^{12,13)}$ The number of studies among young adults and college students is still very limited. Universities and colleges are strategic places to promote healthy lifestyle practices for this young population. College and university life represents an important transition period in which students are establishing their identity and forming lifelong habits. ${ }^{14,15)}$ The aim of the study was to determine the association between body weight perception and weight loss practice among students in nursing colleges.

\section{METHODS}

\section{Study Design and Participants}

The study was conducted from December 2011 to February 2012. The study proposal was approved by the Ethics Committee of Universiti Sains Malaysia, Kelantan, Malaysia. Participants were selected from three private nursing colleges in the state of Kelantan, Malaysia. The selected private nursing colleges are registered in the Ministry of Higher Education of Malaysia. Invitation letters were then sent to the colleges. Permission to conduct the study on the students was granted by the chief executive officers and administrative offices of the respective colleges. The inclusion criteria for the study include age of 18 years or older, at the time of the study, and availability during the data collection period. Those who were not available at the colleges, studying courses other than nursing, and pregnant were excluded from the study. Sample size calculation was based on the study of Cheung et al., ${ }^{7)}$ and the sample size was 318 after considering $20 \%$ of the non-response rate. A total number of 1,015 nursing college students fulfilled the criteria, and 318 out of 1,015 were selected according to the computer-generated random numbers from their college's name list. All of the 318 participants were invited to join the study, and only 297 students agreed and signed the consent to join the study. Hence, the response rate was $93.3 \%$. All participants who consented to the study filled-up the questionnaires, and anthropometric measurement was obtained by a researcher and one trained assistant.

\section{Research Tools}

The self-administered questionnaire consists of sociodemographic data, body weight perception, and weight reduction methods. The sociodemographic data included age, sex, race/ethnicity, marital status, and status of having obese family members.

\section{1) Body weight perception and weight loss practices and methods}

Body weight perception was classified into five categories, underweight, just right, slightly overweight, moderately overweight, and very overweight. Each body weight perception category was represented by BMI cutoff values according to the WHO guideline. The cutoff values are indicated in Table 1. Body weight perceived by participants was then compared with the actual measured BMI.

The participants answered the questions whether they are trying to lose their weight for the past 3 months with "yes" or "no" response. Weight loss practices included food intake restriction, physical exercise, slimming programs, usage of herbs and laxatives, traditional medications, anti-obesity medications, and other methods. The usage of herbs and laxatives and intake of traditional medications are considered as unhealthy methods. ${ }^{16)}$

Table 1. Sociodemographic characteristics and actual body mass index measurement

\begin{tabular}{lc}
\hline Socio-demographic characteristic & Value \\
\hline Age $(\mathrm{y})$ & $21.0 \pm 3.0$ \\
Gender & $267(89.9)$ \\
Female & $30(10.1)$ \\
Male & \\
Race/ethnic & $296(99.7)$ \\
Malays & $1(0.3)$ \\
Chinese & \\
Marital status & $286(96.3)$ \\
Single & $11(3.7)$ \\
Married & \\
Having family members with obesity & $230(77.4)$ \\
No & $67(22.6)$ \\
Yes & \\
Body mass index (kg/m²) & $56(18.8)$ \\
Underweight $(<18.5)$ & $191(64.3)$ \\
Normal $(18.5-24.9)$ & $41(13.8)$ \\
Overweight $(25.0-29.9)$ & $7(2.4)$ \\
Obese I (30.0-34.9) & $2(0.7)$ \\
Obese II (35.0-39.9) & 0 \\
Obese III $(\geq 40.0)$ & \\
\hline
\end{tabular}

Values are presented as mean \pm standard deviation or number (\%). 


\section{2) Anthropometric measurements}

The weight of the participant was measured using a portable digital scale. The participants were instructed to remove their shoes and bags before stepping on the scale. The weight was measured to the nearest $0.1 \mathrm{~kg}$. The standing height was assessed using the maximum vertical stature. A movable head box and measuring tape were used to measure the height. The measuring tape was fixed on the wall which did not have any baseboard below. The participants were instructed to remove their shoes and then stand with their heels touching the wall surface and their feet pointing outward from the wall surface. The participants were instructed to face forward and make sure their backside touched the wall. They were also asked to take a deep breath during the measurement. The height was measured in centimeters and then converted to meters before calculating the actual BMI.

\section{Statistical Analysis}

Data was analyzed using the IBM SPSS ver. 20.0 (IBM Corp., Armonk, NY, USA). Descriptive analysis was used for demographic data characteristics. Categorical variables are expressed as percentage, and numerical variables are expressed as mean \pm standard deviation. Crosstabulations were developed for the actual BMI of the participants and their body weight perception.

All continuous variables are expressed as mean and $95 \%$ confidence interval (CI). Frequency and percentage for categorical variables were calculated. Categories with a small sample size and skewed distribu- tion were noted. Meaningful combinations of categories were done when indicated.

A multiple logistic regression analysis was carried out with weight loss practice as the dependent variable. The independent variables are body weight perception, sex, marital status, and status of having obese family members. All independent variables were simultaneously included in the regression model regardless of their statistical significance, and since this is a confirmatory analysis, no variable selection was done. The preliminary main effect model was obtained. All the possible 2-way interactions were verified, and variance inflation factors were obtained to check for multicollinearity. The preliminary final model was obtained. The model fit was tested by Hosmer and Lemeshow goodness of fit test. The model is a perfect fit if the P-value approached 1 . The classification table and receiver operating characteristic (ROC) curve were used to determine the model fit. The high overall percentage in the classification table and area under the curve toward 1 in the ROC curve showed that the model was fit. A P-value $<0.05$ was considered statistically significant.

\section{RESULTS}

Sociodemographic characteristics and the actual BMI measurement of the participants are shown in Table 1. Majority of the participants had normal BMI (64.3\%), and $18.8 \%$ were underweight. None of the participants had obese type III. Cross-tabulation analysis between

Table 2. Comparison of body weight perception per actual measured BMI

\begin{tabular}{|c|c|c|c|c|c|c|}
\hline \multirow[b]{2}{*}{ Actual measured BMl } & \multicolumn{6}{|c|}{ Body weight perception } \\
\hline & Underweight & Just right & Slightly overweight & $\begin{array}{l}\text { Moderately } \\
\text { overweight }\end{array}$ & Very overweight & Total $(\%)$ \\
\hline Underweight & 46 & 8 & 2 & 0 & 0 & 56 \\
\hline Normal & 15 & 97 & 62 & 17 & 0 & 191 \\
\hline Overweight & 1 & 5 & 14 & 18 & 3 & 41 \\
\hline Obese type I & 0 & 0 & 1 & 3 & 3 & 7 \\
\hline Obese type II and obese type III & 0 & 0 & 0 & 1 & 1 & 2 \\
\hline \multicolumn{7}{|c|}{ Accuracy of perceived body weight per actual BMI } \\
\hline Correct & & & & & & $161(54.2)$ \\
\hline Incorrect & & & & & & $136(45.8)$ \\
\hline
\end{tabular}

Underweight, BMI < 18.5 kg/m²; normal, BMl 18.5-24.9 kg/m²; overweight, BMl 25.0-29.9 kg/m²; obese type I, BMl 30.0-34.9 kg/m²; obese type II, BMI 35.0-39.9 kg/m²; obese type III, BMI $\geq 40.0 \mathrm{~kg} / \mathrm{m}^{2}$.

BMl, body mass index.

Table 3. Association between body weight perception and weight loss practice using simple and multiple logistic regression models

\begin{tabular}{|c|c|c|c|c|c|c|c|c|}
\hline \multirow{2}{*}{ Variable } & \multicolumn{4}{|c|}{ Simple logistic regression } & \multicolumn{4}{|c|}{ Multiple logistic regression } \\
\hline & $\mathrm{b}$ & Crude OR (95\% Cl) & Wald statistic & P-value & $b$ & Adjusted OR (95\% Cl) & Wald statistic* & P-value \\
\hline Correct body weight perception & -1.17 & $0.3(0.18-0.47)$ & 23.01 & $<0.001$ & -1.13 & $0.31(0.19-0.50)$ & 23.14 & $<0.001$ \\
\hline Gender (female) & 0.52 & $1.68(0.78-3.62)$ & 1.74 & 0.19 & 0.40 & $1.49(0.67-3.33)$ & 0.96 & 0.33 \\
\hline Married & 0.13 & $1.14(0.33-3.80)$ & 0.04 & 0.84 & 0.02 & $1.02(0.29-3.59)$ & 0.00 & 0.98 \\
\hline Family members with obesity & 0.59 & $1.80(1.03-3.15)$ & 4.26 & 0.04 & 0.49 & $1.63(0.91-2.92)$ & 2.73 & 0.09 \\
\hline
\end{tabular}

Multicollinearity and interaction term were checked and not found. Hosmer-Lemeshow test ( $\mathrm{P}=0.752)$, classification table (overall percentage $=64.0 \%$ ), and area under the receiver operating characteristic curve (66.4\%) were applied to check the model fitness.

$\mathrm{b}$, regression coefficient; $\mathrm{OR}$, odds ratio; $\mathrm{Cl}$, confidence interval.

*Likelihood ratio statistic. 
Table 4. Weight loss methods

\begin{tabular}{lc}
\hline \multicolumn{1}{c}{ Methods } & No. (\%) \\
\hline Food intake restriction & $126(42.4)$ \\
Physical exercise & $75(25.3)$ \\
Slimming programs & $14(4.7)$ \\
Herbs and laxatives & $11(3.7)$ \\
Traditional medications & $10(3.4)$ \\
Anti-obesity medications & $2(0.7)$ \\
Others & $2(0.7)$ \\
\hline
\end{tabular}

body weight perception and actual measured BMI found that over half of the participants had correct body weight perception (54.2\%) (Table 2). However, nearly half of the participants had incorrect body weight perception, and majority of the participants (83\%) overestimated their weight when compared to the actual BMI.

The simple and multiple logistic regression models show significant association between correct body weight perception and weight loss practice (crude odds ratio [OR], 0.3; 95\% CI, 0.18-0.47; $\mathrm{P}<0.001$ and adjusted OR, 0.31; 95\% CI, 0.19-0.50; $\mathrm{P}<0.001$ ) when adjusted for marital status, sex, and status of having obese family members (Table 3). Those who correctly perceived their body weight were less likely to engage in weight loss practice.

Half of the participants (51.5\%) were engaged in weight loss practice. Weight loss methods are shown in the Table 4 . Food intake restriction $(42.4 \%)$ is the most popular method chosen by the nursing students to reduce their weight. Physical exercise (25.3\%) was the second choice among the methods of choice to reduce their weight. There are a small number of participants who still engaged in unhealthy weight loss practice.

\section{DISCUSSION}

The results of this study show that body weight perception is associated with weight loss practice among nursing college students. The results are similar to those of studies that found that weight perception has a strong relationship with weight loss behavior and is independent of the actual body weight. ${ }^{17-19)}$ A study by Yost et al. ${ }^{10)}$ among adolescent groups found that accurate weight perceptions are associated with trying to lose weight, which is similar to the result of this study. The results of this study show that participants were less likely to engage in weight loss practices if the weight is correctly perceived per the actual BMI. Several other studies reported that there are a significant number of overweight persons who do not practice any weight control activities and then there were those who had normal weight or were underweight who engaged in weight control activities. ${ }^{5,17)}$ In contrast to this study, majority of the participants who were overweight in the BMI measurement did practice weight loss methods. There were also participants who had normal actual BMI who were still engaged in weight loss activities. Most of the participants in this study actually had overestimated their weight. There are a small number of participants who were engaged in unhealthy weight loss methods. Concern should be given to this group as they may continuously engage in unnecessary weight loss practices that can be harmful to their health. A study by Wharton et al. ${ }^{14)}$ demonstrated that women are more likely to suffer distorted body image and interested in weight loss activities compared to men. Inaccurate body weight perceptions may predispose individuals to psychological and behavioral issues such as depression, bulimia, and anorexia nervosa, which accompany the concern about body weight. ${ }^{20)}$ In this study, only a small number of participants with underweight BMI engaged in weight loss activities, and a small number of college students chose unhealthy weight loss practice. Thus, promoting healthy weight management should be delivered and emphasized in order to avoid eating disorders and unnecessary dieting, which compromise their health. A study suggested that female college students would benefit from open discussion about healthy and effective weight loss practice with health educators regardless of their weight status. ${ }^{21)}$ Health educators should be available in the colleges for the discussion. A majority of the participants in this study chose food intake restriction as a method to reduce their weight. Lowry et al. ${ }^{22)}$ found that high school students like to choose exercise and fat intake restriction as preferred methods to reduce their weight. The finding is also similar to this study. College and high school students preferred dieting with restricting their food intake and exercise. ${ }^{21,22)}$ This is practiced by both female and male teenagers. ${ }^{23)}$ Both physical activity and caloric intake restriction are recommended for weight loss. ${ }^{24)}$ Other methods recommended to reduce weight include not skipping breakfast, regular self-monitoring on weight, and having a consistent eating pattern. ${ }^{25)}$

As a conclusion, body weight perceptions play an important role in motivating to practice weight loss activities. Awareness about using BMI in weight management should be emphasized. Body weight perception is not the only predominant factor in determining the willingness to practice weight loss activities. Other factors such as knowledge, self-efficacy, and social support are other important elements in weight management behavior and weight loss practice among the young populations. ${ }^{14,26)}$ These factors can be considered in future studies. There are some limitations in this study. The results only represent students from private nursing colleges, and most of our participants are female.

\section{CONFLICT OF INTEREST}

No potential conflict of interest relevant to this article was reported.

\section{REFERENCES}

1. World Health Organization. Global status report on noncommunicable diseases 2014. Geneva: World Health Organization; 2014.

2. Haslam DW, James WP. Obesity. Lancet 2005;366:1197-209.

3. Rampal L, Rampal S, Khor GL, Zain AM, Ooyub SB, Rahmat RB, et al. A national study on the prevalence of obesity among 16,127 Malaysians. Asia Pac J Clin Nutr 2007;16:561-6. 
4. Simkin-Silverman LR, Conroy MB, King WC. Treatment of overweight and obesity in primary care practice: current evidence and future directions. Am J Lifestyle Med 2008;2:296-304.

5. Wardle J, Haase AM, Steptoe A. Body image and weight control in young adults: international comparisons in university students from 22 countries. Int J Obes (Lond) 2006;30:644-51.

6. Patton GC, Carlin JB, Shao Q, Hibbert ME, Rosier M, Selzer R, et al. Adolescent dieting: healthy weight control or borderline eating disorder? J Child Psychol Psychiatry 1997;38:299-306.

7. Cheung PC, Ip PL, Lam ST, Bibby H. A study on body weight perception and weight control behaviours among adolescents in Hong Kong. Hong Kong Med J 2007;13:16-21.

8. Khor GL, Zalilah MS, Phan YY, Ang M, Maznah B, Norimah AK. Perceptions of body image among Malaysian male and female adolescents. Singapore Med J 2009;50:303-11.

9. O'Dea JA, Abraham S. Knowledge, beliefs, attitudes, and behaviors related to weight control, eating disorders, and body image in Australian trainee home economics and physical education teachers. J Nutr Educ 2001;33:332-40.

10. Yost J, Krainovich-Miller B, Budin W, Norman R. Assessing weight perception accuracy to promote weight loss among U.S. female adolescents: a secondary analysis. BMC Public Health 2010;10:465.

11. Duncan DT, Wolin KY, Scharoun-Lee M, Ding EL, Warner ET, Bennett GG. Does perception equal reality?: weight misperception in relation to weight-related attitudes and behaviors among overweight and obese US adults. Int J Behav Nutr Phys Act 2011;8:20.

12. Cai L, Zhang T, Ma J, Ma L, Jing J, Chen Y. Self-perception of weight status and its association with weight-related knowledge, attitudes, and behaviors among Chinese children in Guangzhou. J Epidemiol 2017;27:338-45.

13. Lim H, Wang Y. Body weight misperception patterns and their association with health-related factors among adolescents in South Korea. Obesity (Silver Spring) 2013;21:2596-603.

14. Wharton CM, Adams T, Hampl JS. Weight loss practices and body weight perceptions among US college students. J Am Coll Health
2008;56:579-84.

15. Cullen KW, Koehly LM, Anderson C, Baranowski T, Prokhorov A, Basen-Engquist $\mathrm{K}$, et al. Gender differences in chronic disease risk behaviors through the transition out of high school. Am J Prev Med 1999;17:1-7.

16. Eisenberg ME, Neumark-Sztainer D, Story M, Perry C. The role of social norms and friends' influences on unhealthy weight-control behaviors among adolescent girls. Soc Sci Med 2005;60:1165-73.

17. Kim KH. Religion, weight perception, and weight control behavior. Eat Behav 2007;8:121-31.

18. Budd GM, Mariotti M, Graff D, Falkenstein K. Health care professionals' attitudes about obesity: an integrative review. Appl Nurs Res 2011;24:127-37.

19. Ogden J, Hoppe R. Changing practice nurses' management of obesity. J Hum Nutr Diet 1998;11:249-56.

20. Khambalia A, Hardy LL, Bauman A. Accuracy of weight perception, life-style behaviours and psychological distress among overweight and obese adolescents. J Paediatr Child Health 2012;48:220-7.

21. Malinauskas BM, Raedeke TD, Aeby VG, Smith JL, Dallas MB. Dieting practices, weight perceptions, and body composition: a comparison of normal weight, overweight, and obese college females. Nutr J 2006;5:11.

22. Lowry R, Galuska DA, Fulton JE, Wechsler H, Kann L, Collins JL. Physical activity, food choice, and weight management goals and practices among US college students. Am J Prev Med 2000;18:18-27.

23. Bhurtun DD, Jeewon R. Body weight perception and weight control practices among teenagers. ISRN Nutr 2013;2013:395125.

24. Swift DL, Johannsen NM, Lavie CJ, Earnest CP, Church TS. The role of exercise and physical activity in weight loss and maintenance. Prog Cardiovasc Dis 2014;56:441-7.

25. Wing RR, Phelan S. Long-term weight loss maintenance. Am J Clin Nutr 2005;82(1 Suppl):222S-225S.

26. Gruber AJ, Pope HG Jr, Lalonde JK, Hudson JI. Why do young women diet?: the roles of body fat, body perception, and body ideal. J Clin Psychiatry 2001;62:609-11. 